\title{
Morphometry of adults and larval stages of Cicadatra persica (Cicadidae: Hemiptera) distributed in Erneh, Syria
}

\author{
M.A. Derdar, ${ }^{1}$ H.M.R. Belal ${ }^{2}$ \\ ${ }^{1}$ Department of Insects Research, Administration of Plant Protection Research, General Commission \\ for Scientific Agricultural Research, Damascus; ${ }^{2}$ Department Plant Protection, Faculty of Agriculture, \\ University of Damascus, Damascus, Syria
}

\begin{abstract}
This study was conducted in order to describe and measure the morphological characters of adults and larval stages of the cicada Cicadatra persica distributed in Erneh, Syria. Eggs, newly hatched nymphs, fully developed nymphs, exuviae and adults were described and measured. The mean lengths of eggs $(1.9 \pm 0.1 \mathrm{~mm})$ were the same as newly hatched nymphs $(1.8 \pm 0.174 \mathrm{~mm})$, whereas the mean length of the fully developed nymphs $(3.1 \pm 0.185 \mathrm{~cm})$ was longer than the adults. Several parts of adults' body (males and females) were measured. The results show that the mean of females bodies $(2.60 \pm 0.118$ $\mathrm{cm}$ ) were larger than males ones $(2.45 \pm 0.192 \mathrm{~cm})$, nevertheless, there were no significant differences between them.
\end{abstract}

Correspondence: Marah A. Derdar, Department of Insects Research, Administration of Plant Protection Research, General Commission for Scientific Agricultural Research, Damascus, Syria.

E-mail: marah.derdar@hotmail.com

Hamzeh M.R. Belal, Department Plant Protection, Faculty of Agriculture, University of Damascus, Damascus, Syria.

E-mail: cecehamz@scs-net.org

Key words: Cicadidae; morphological characters; egg nest; apple orchards; Erneh.

Acknowledgements: the General Commission for Scientific Agricultural Research supported this research. We thank the Biological Control Studies and Research Center, which is dependent to the Faculty of Agriculture, University of Damascus, Syria. We also thank the farmer Ismael Masoud in village of Erneh for permitting us to collect samples from his orchards.

Received for publication: 16 December 2014.

Revision received: 22 March 2015.

Accepted for publication: 13 October 2015.

(C) Copyright M.A. Derdar and H.M.R. Belal, 2016

Licensee PAGEPress, Italy

Journal of Entomological and Acarological Research 2016; $48: 4911$

doi:10.4081/jear.2016.4911

This article is distributed under the terms of the Creative Commons Attribution Noncommercial License (by-nc 4.0) which permits any noncommercial use, distribution, and reproduction in any medium, provided the original author(s) and source are credited.

\section{Introduction}

Little is known about the species Cicadatra persica Kirkaldy 1909, which is distributed in Middle East countries and surrounding areas. $C$. persica was reported for the first time in Macedonia and its song was recorded and analyzed (Gogala \& Trilar, 1998, 2003). Kartal \& Zeybekoğlu (1996) described the internal and external structure of the reproductive system of its adults.

Researches on $C$. persica distribution in Syria are limited. The only researches conducted on this species were by Dardar et al. (2012, 2013a, 2013b), Dardar and Belal (2013) emphasizing the morphological differences among egg nests and adult individuals of $C$. persica. In this study, pictures are given for adults, larval stages and eggs of $C$. persica and some morphological characters are measured.

\section{Materials and methods}

\section{Collecting individuals}

Adults and larval stages of $C$. persica were collected from apple fruit orchards in the village Erneh that is located in Al-Sheikh Mountain in the south west of Syria.

The eggs were collected by cutting the twigs that hold egg nests from apple fruit orchards.

The newly hatched nymphs were collected by using the traps described by Dardar et al. (2012) and fixed in an ethanol and glycerin solution to maintain body soft to aid the study with a stereomicroscope.

The fully developed nymphs were collected by digging in the soil during adults' emergence period. Adults were collected by hand and with emergence traps described by Dardar et al. (2012) from the orchards at sunset and sunrise times, when the insects are collected in larger numbers.

\section{Morphometric study}

Morphological characters of adults and larval stages identified by Moulds (2005) were studied by using a stereomicroscope (Olympus SZ61, optical lens: 10X, body lens: $2 \mathrm{X}$ ).

The length of body of adults ( $n=11$ males, $n=11$ females) and fully development nymphs $(\mathrm{n}=8)$ was measured in $\mathrm{cm}$ by a ruler; 34 and 30 morphological characters of males $(\mathrm{n}=11)$ and females $(\mathrm{n}=11)$ of $C$. persica were measured.

The length of different parts of body of adults was measured with the stereomicroscope with a magnification of 0.67 . The length of the body and different parts of the body of the newly hatched nymphs $(n=6)$ was also measured with a magnification of 4.5.

The real length of different part of the body was measured in $\mathrm{mm}$. 


\section{Statistical analysis}

Means and standard deviations were calculated for the length of different parts of adults' body and larval stages using SPSS software (IBM Corp., Armonk, NY, USA).

Two independent samples t-test were carried out for the length of some morphological characters in order to compare males and females of $C$. persica.

\section{Results and discussion}

\section{Morphometric study}

\section{The eggs}

The color of the newly laid eggs is white (Figure 1) when newly laid and then it changes gradually into black light yellow (Figure 2), dark yellow, light rosy, and completely rosy (Figure 3 ) before hatching.

The mean length of the egg of $C$. persica was $0.1 \pm 1.9 \mathrm{~mm}(\mathrm{n}=6)$.

\section{The newly hatched nymph}

The body of the nymph is rosy. The head is conical and ends with a long rostrum. Ocelli are absent; there are two pairs of eyes and antennas on the both lateral sides of the head (Figure 4). It has sucking mouthparts. The pronotum is well developed and longer than mesonotum and metanotum in order to support the fore legs to dig in the soil. The wing pads are absent.

The sixth pairs of legs are transparent. The fore femur is large and has a vertical spine on the lateral side of the leg. In this age, we cannot distinguish between the genital organs of males and females. Each antenna consists of 7 transparent segments (Figure 5).

The lengths of 24 morphological characters for newly hatched nymphs ( $\mathrm{n}=6)$ of $C$. persica were measured (Table 1$)$.

\section{The fully development nymph}

The color of the body is brown (Figure 6). The head is triangular and held two pairs of eyes and antennas. Each antenna consists of 7 segments. The ocelli are absent. It has sucking mouthparts. Mesonotum is larger than pronotum and hold fore wing pads. The metanotum is small and hold the hind wing pads (Figure 7). There are six pairs of legs, and the fore legs hold 3 spines that are different in size on the lateral side of the leg (Figure 8). The abdomen consists of 8 segments end with the genital organ.

The mean length of the body's nymph was $3.1 \pm 0.185 \mathrm{~cm}(\mathrm{n}=8)$.

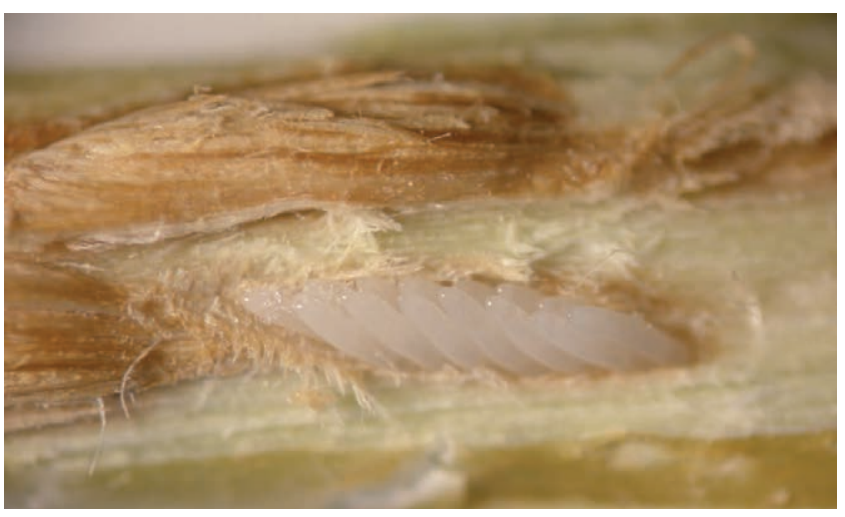

Figure 1. White eggs.

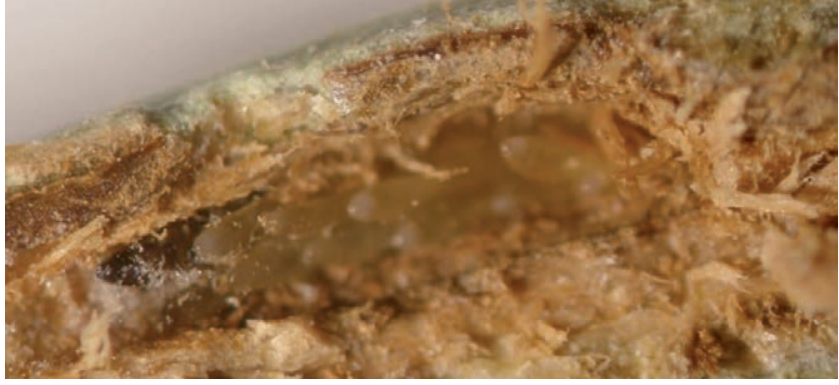

Figure 2. Yellowish eggs.

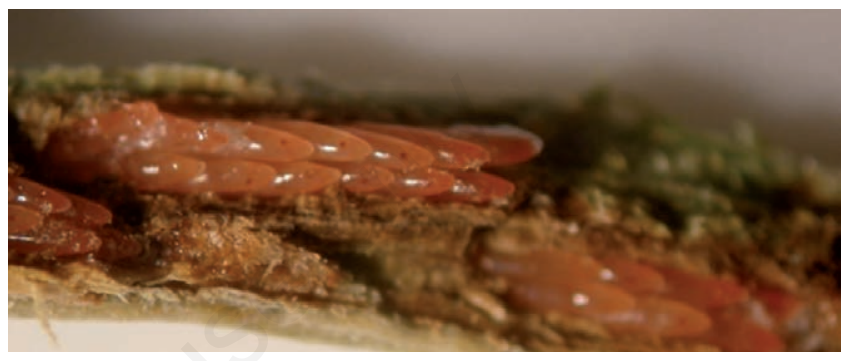

Figure 3. Rosy eggs.

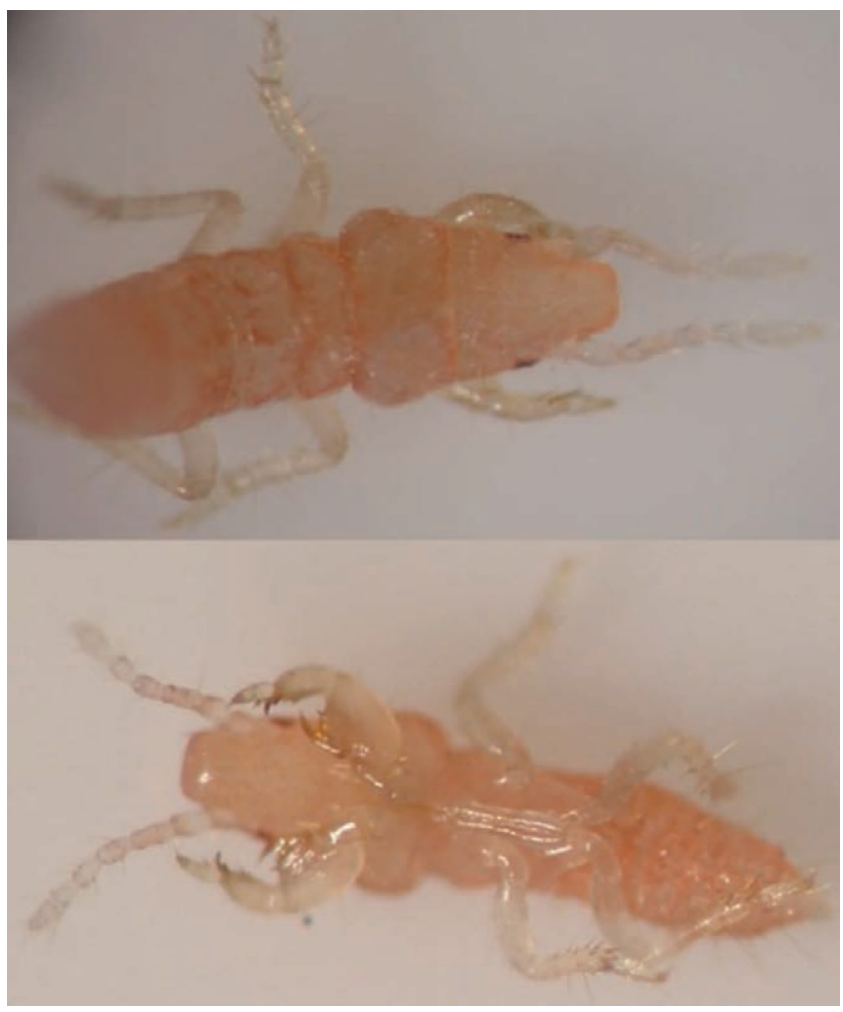

Figure 4. The newly hatched nymph. 


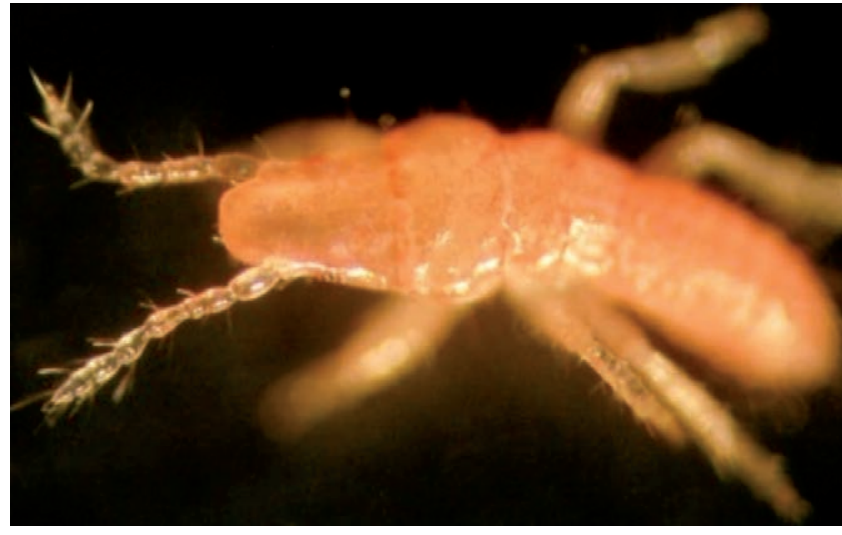

Figure 5. Antenna of the newly hatched nymph.

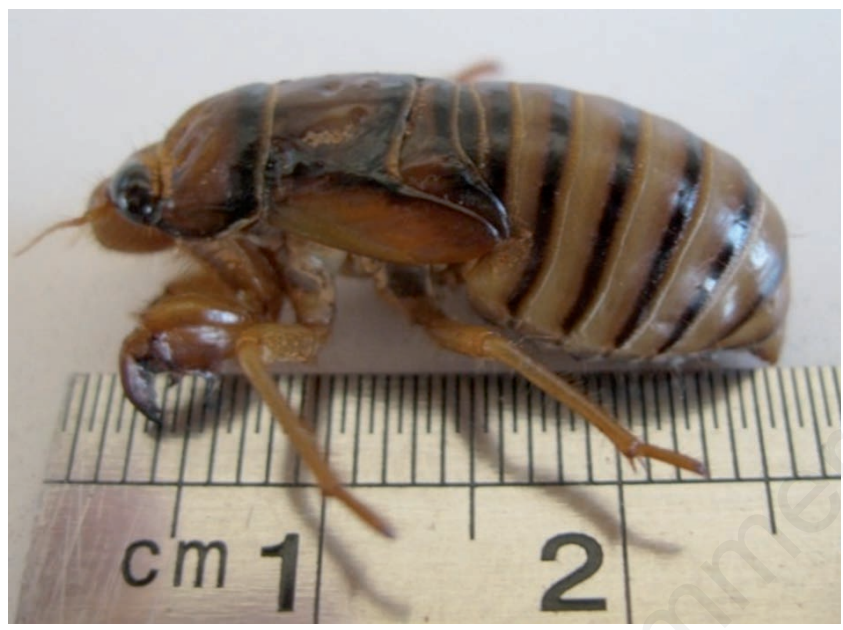

Figure 6. The full development nymph.

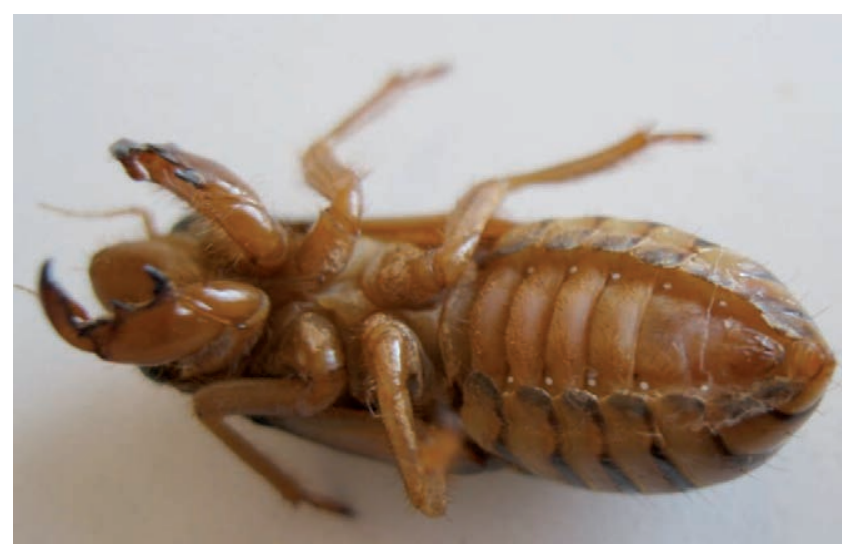

Figure 7. Full development nymph (ventral view).

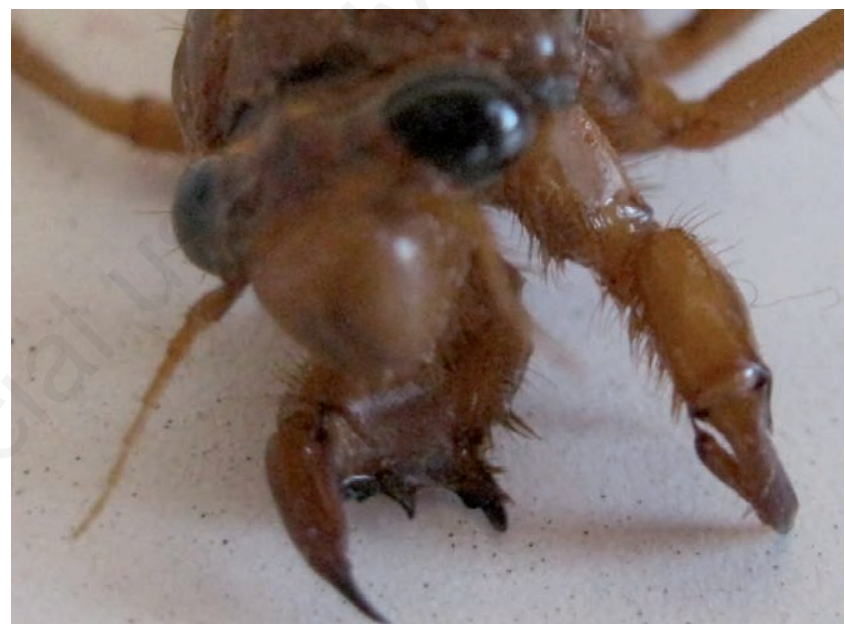

Figure 8. Fore legs of the full development nymph.

Table 1. The measurements (in $\mathrm{mm}$ ) of the morphological characters for newly hatched nymphs of Cicadatra persica (n=6).

\begin{tabular}{|c|c|c|c|}
\hline The character & Mean \pm Std. & The character & Mean \pm Std. \\
\hline Body length & $1.8 \pm 0.174$ & Tibia 3 & $0.34 \pm 0.014$ \\
\hline Width of head capsulate & $0.30 \pm 0.025$ & Tarsi 1 & $0.11 \pm 0.00$ \\
\hline Pronotum width & $0.375 \pm 0.0748$ & Tarsi 2 & $0.12 \pm 0.026$ \\
\hline Coxa 1 & $0.22 \pm 0.031$ & Tarsi 3 & $0.15 \pm 0.018$ \\
\hline Coxa 2 & $0.16 \pm 0.035$ & Claw 1 & $0.04 \pm 0.011$ \\
\hline Coxa 3 & $0.22 \pm 0.031$ & Claw 2 & $0.05 \pm 0.006$ \\
\hline Trochanter 1 & $0.16 \pm 0.027$ & Claw 3 & $0.05 \pm 0.011$ \\
\hline Trochanter 2 & $0.13 \pm 0.025$ & Scape & $0.11 \pm 0.008$ \\
\hline Trochanter 3 & $0.12 \pm 0.030$ & \multirow{6}{*}{ Segments of flagellum of antenna } & $0.11 \pm 0.010$ \\
\hline Femur 1 & $0.25 \pm 0.033$ & & $10.10 \pm 0.005$ \\
\hline Femur 2 & $0.21 \pm 0.070$ & & $2 \quad 0.08 \pm 0.009$ \\
\hline Femur 3 & $0.27 \pm 0.034$ & & $\begin{array}{ll}3 & 0.07 \pm 0.010\end{array}$ \\
\hline Tibia 1 & $0.20 \pm 0.034$ & & $4 \quad 0.05 \pm 0.005$ \\
\hline Tibia 2 & $0.25 \pm 0.021$ & & $\begin{array}{ll}5 & 0.05 \pm 0.005\end{array}$ \\
\hline
\end{tabular}

Std., standard deviation. 


\section{The adult}

The adult emerges from the final stage of nymph by molting that takes about 30-40 min. The newly emerged adult is soft and dull. It remains quit at rest without any movement on her exuvia, and takes her natural color and her wings begin to harden gradually (Figure 9). Then it flies and leaves its exuvia (Figure 10) on the soil surface, trunks, or weeds.

The body of adult is black; the head is triangular and hold two pair of

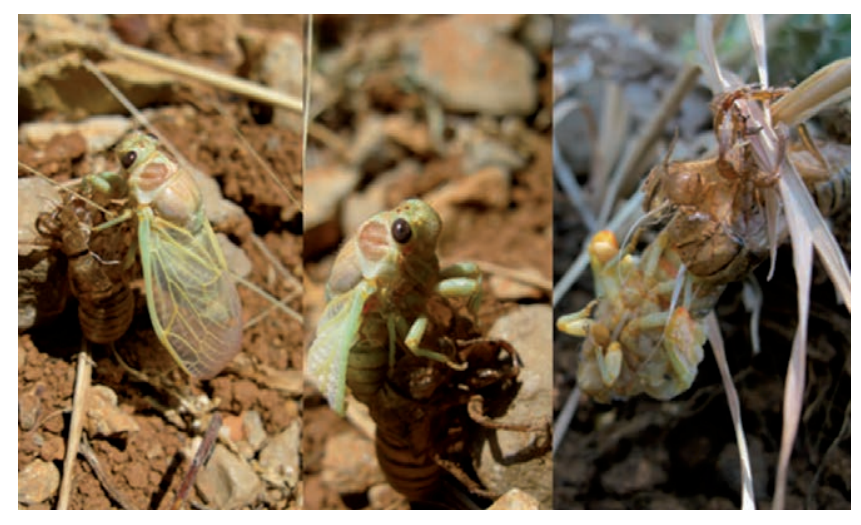

Figure 9. Molting.

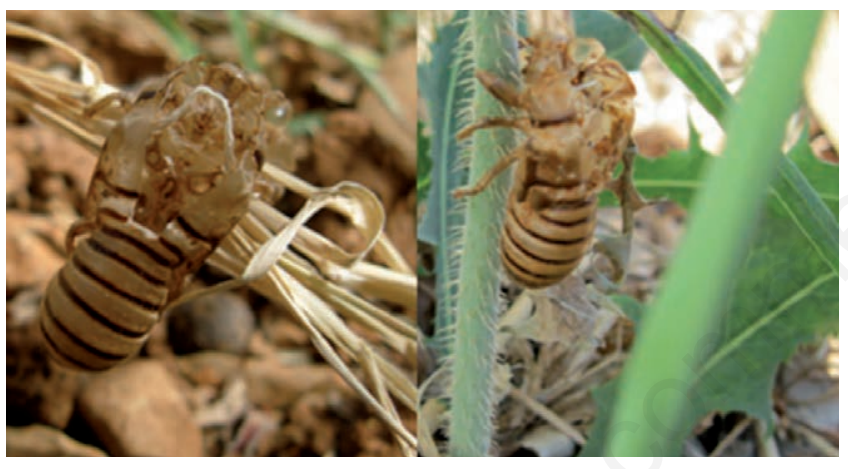

Figure 10. Exuviae of Cicadatra persica.

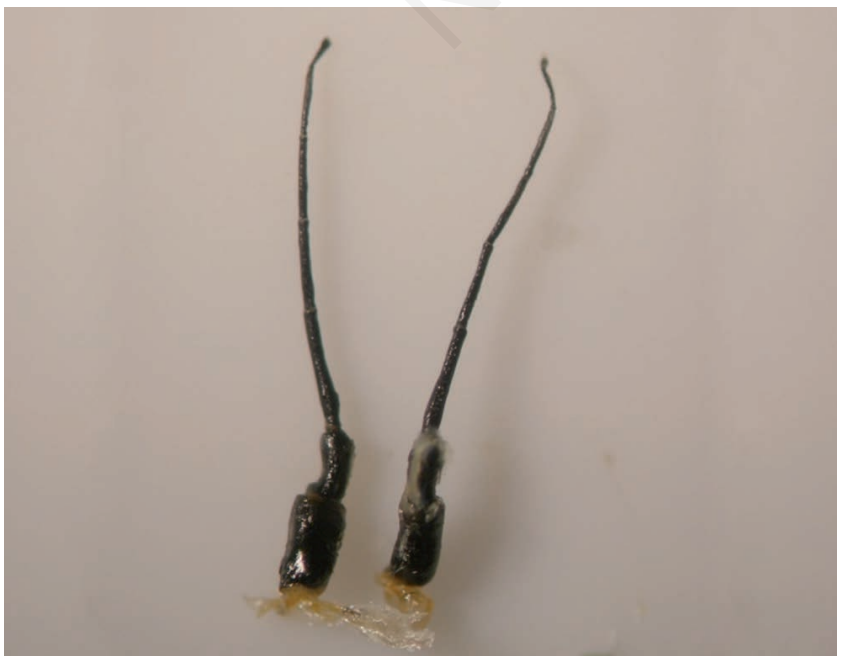

Figure 11. The antenna of Cicadatra persica. compound eyes, 3 ocelli and one pair of antennae. Each antenna consists of 5 segments (Figure 11). It has sucking mouthparts. The wings are membranous with black veins and orange color at the base. The abdomen consists of 8 segments end with the genital organ.

\section{The male}

Thirty-four morphological characters for males $(\mathrm{n}=11)$ of $C$. persica were measured (Table 2).

\section{The female}

Thirty morphological characters for females $(\mathrm{n}=11)$ of $C$. persica were measured (Table 3 ).

Table 2. Measures (in $\mathrm{cm}$ ) of the morphological characters for males $(n=11)$ of Cicadatra persica.

\begin{tabular}{lccc}
\hline The character & Mean \pm Std. & The character & Mean \pm Std. \\
Body length & $2.45 \pm 0.192$ & Coxa 2 & $3.61 \pm 0.305$ \\
Width of head capsulate & $9.04 \pm 1.162$ & Coxa 3 & $3.45 \pm 0.317$ \\
\hline Pronotum width & $11.34 \pm 1.248$ & Trochanter 1 & $3.10 \pm 0.349$ \\
Wings span & $7.02 \pm 0.199$ & Trochanter 2 & $2.40 \pm 0.366$ \\
\hline Fore wing & $3.20 \pm 0.109$ & Trochanter 3 & $2.04 \pm 0.258$ \\
Hind wing & $1.809 \pm 0.083$ & Femur 1 & $4.78 \pm 0.606$ \\
\hline Post clypeus & $4.36 \pm 0.445$ & Femur 2 & $5.18 \pm 0.611$ \\
Operculum & $6.96 \pm 1.000$ & Femur 3 & $5.30 \pm 0.761$ \\
\hline Aedeagus & $5.76 \pm 0.998$ & Tibia 1 & $5.18 \pm 0.663$ \\
Pygofer & $6.454 \pm 0.656$ & Tibia 2 & $6.68 \pm 0.791$ \\
\hline Upper lap & $0.61 \pm 0.255$ & Tibia 3 & $7.78 \pm 0.885$ \\
Basal lap & $0.57 \pm 0.127$ & Tarsi 1 & $2.61 \pm 0.353$ \\
\hline Dorsal peak of pygofer & $1.26 \pm 0.262$ & Tarsi 2 & $2.61 \pm 0.321$ \\
Claspers & $1.80 \pm 0.475$ & Tarsi 3 & $2.64 \pm 0.443$ \\
\hline Uncus & $0.46 \pm 0.112$ & Claw 1 & $1.2 \pm 1.924$ \\
Sternite vIII & $6.91 \pm 0.702$ & Claw 2 & $0.72 \pm 0.075$ \\
\hline Coxa 1 & $5.49 \pm 0.737$ & Claw 3 & $0.70 \pm 0.077$ \\
\hline
\end{tabular}

Std., standard deviation.

Table 3. Measures (in $\mathrm{cm}$ ) of the morphological characters for females $(n=11)$ of Cicadatra persica.

\begin{tabular}{lccc} 
The character & Mean \pm Std. & The character & Mean \pm Std. \\
Body length & $2.60 \pm 0.118$ & Trochanter 1 & $2.88 \pm 0.252$ \\
Width of head capsulate & $8.20 \pm 0.340$ & Trochanter 2 & $2.17 \pm 0.210$ \\
\hline Pronotum width & $10.91 \pm 0.712$ & Trochanter 3 & $1.82 \pm 0.236$ \\
Wings span & $7.04 \pm 0.311$ & Femur 1 & $4.34 \pm 0.238$ \\
\hline Fore wing & $3.19 \pm 0.158$ & Femur 2 & $4.60 \pm 0.190$ \\
Hind wing & $1.84 \pm 0.067$ & Femur 3 & $4.77 \pm 0.253$ \\
\hline Post clypeus & $3.94 \pm 0.298$ & Tibia 1 & $4.55 \pm 0.225$ \\
Ovipositor & $9.68 \pm 0.531$ & Tibia 2 & $5.78 \pm 0.646$ \\
\hline Abdominal segment & $9.30 \pm 0.703$ & Tibia 3 & $6.97 \pm 0.320$ \\
Ovipositor sheath & $3.84 \pm 0.361$ & Tarsi 1 & $2.34 \pm 0.192$ \\
\hline Valvifer 2 & $4.97 \pm 0.450$ & Tarsi 2 & $2.34 \pm 0.163$ \\
Dorsal peak & $0.94 \pm 0.143$ & Tarsi 3 & $2.34 \pm 0.197$ \\
\hline Coxa 1 & $4.71 \pm 0.359$ & Claw 1 & $0.61 \pm 0.070$ \\
Coxa 2 & $3.45 \pm 0.163$ & Claw 2 & $0.64 \pm 0.052$ \\
\hline Coxa 3 & $3.33 \pm 0.168$ & Claw 3 & $0.62 \pm 0.075$ \\
\hline St
\end{tabular}

Std., standard deviation. 


\section{Conclusions}

There was no significant differences in the body length, wingspan, or pronotum between males and females of $C$. cicadatra $(\mathrm{P}=0.279$, $\mathrm{P}=0.148, \mathrm{P}=0.251)$. However, the results show that there were significant differences in the width of head's capsulate and length of the third tibia ( $P=0.001, P=0.001$ ); the mean width of head's capsulate of the male was bigger than female's one, while the mean length of the third tibia of the male was bigger than female's one.

\section{References}

DARDAR M.A., BELAL H.M.R., 2013 - Morphological differences among egg nests and adult individuals of Cicadatra persica (Hemiptera: Cicadidae), distributed in Erneh, Syria. - ZooKeys. 319: 11-25.

DARDAR M.A., BELAL H.M.R., BASHEER A.M., 2012 - Observation on some biological aspects of Cicadatra persica (Cicadidae:
Hemiptera) in apple fruit orchards in Erneh, Syria. - J. Entomol. Acarol. Res. 44: 56-59.

DARDAR M.A., BELAL H.M.R., BASHEER A.M., 2013a - A study on egg nests of Cicadatra persica (Hemiptera: Cicadidae) distributed in Erneh, Syria. - Ann. Soc. Entomol Fr. 49: 273-276.

DARDAR M.A., BELAL H.M.R., BASHEER A.M., 2013b - Occurance of Cicadatra persica on apple trees Malus domestica in Erneh, Syria. J. Insect Sci. 13: 1-5.

GOGALA M., TRILAR T., 1998 - First record of the Cicadatra persica Kırkaldy. 1909 from Macedonia, with description of its song. - Acta Entomol. Sloven. 6: 5-15.

GOGALA M., TRILAR T., 2003 - Video analysis of wing clicking in cicadas of the genera Cicadatra and Pagiphora (Homoptera: Auchenorrhyncha: Cicadodea). - Acta Entomol. Sloven. 11: 5-15.

KARTAL V., ZEYBEKOĞLU Ü., 1996 - An investigation on the morphology of genital organs and oviposition capacity of Cicadatra persica Kirkaldy, 1909 (Cicadidae, Hemiptera). - Zoology. 1: 59-62.

MOULDS M.S., 2005 - An appraisal of the higher classification of cicadas (Hemiptera: Cicadoidea) with special reference to the Australian fauna. - Records Austr. Museum. 57: 375-446. 